\title{
A PORNOGRAFIA DE VINGANÇA COMO INSTRUMENTO DE VIOLÊNCIA DE GÊNERO
}

\section{REVENGE PORN AS AN INSTRUMENT OF GENDER VIOLENCE}

\author{
Maria Bueno Barbosa* \\ Priscilla Menezes Santos*"
}

\begin{abstract}
Resumo
O estudo busca refletir sobre a prática da pornografia de vingança, entendendo conceitualmente o objeto, perpassando brevemente pelo contexto sociológico das relações modernas. Discute-se sobre a dualidade existente entre a liberdade de expressão no ciberespaço e os danos aos direitos das mulheres. Nesse sentido, pretende-se apresentar uma análise da responsabilidade civil de provedores de aplicação sobre conteúdo produzido por terceiros no caso da pornografia de vingança, como instrumento de violência de gênero, perpassando por uma análise legislativa e jurisprudencial do STJ, além de analisar e propor mecanismos jurídicos cíveis de repressão à prática, com inspiração em mecanismos bem-sucedidos em outros países, por meio do direito comparado.
\end{abstract}

Palavras-chave: Pornografia de vingança; Violência de gênero; Responsabilidade Civil; Direito à desindexação; ciberespaço.

\begin{abstract}
The study aims to address the practice of revenge porn, comprehending the sociological context of modern relationships, also discussing the duality between freedom of expression in cyberspace and damage to fundamental women rights. In this sense, we intend to analyze the civil liability of application providers on contents produced by third parties in the case of revenge pornography, as gender violence, going through a legislative and jurisprudential analysis of the Brazilian Superior Court of Justice, aiming at the proposition of legal mechanisms that would facilitate the repression of those practices, inspired by successful mechanisms through comparative law.
\end{abstract}

Artigo submetido em 28 de junho de 2020 e aprovado em 12 de agosto de 2020

\footnotetext{
* Doutora e Mestre em Direito Público pelo Programa de Pós-graduação em Direito, da Pontifícia Universidade Católica de Minas Gerais. Professora Titular I no Ibmec|BH, na Pós-graduação em Direito e Tecnologia da Faculdade Arnaldo e na pós-graduação em Direito, Inovação e Tecnologia da Escola Superior de Advocacia, e de Direito e Empreendedorismo no IPROJUDE. Analista internacional (PUCMinas). Advogada, Diretora de Relações Institucionais da Comissão de Direito para Startups e Secretária-Adjunta da Comissão de Direito Internacional da OAB/MG. E-mail de contato: mariabueno@gmail.com.

** Bacharel em Direito pela Universidade Estadual de Montes Claros. Especialista em Direito Público pela Pontifícia Universidade Católica de Minas Gerais. Pós-graduanda em Direito e Tecnologia pela Faculdade Arnaldo Janssen e em Direito Empresarial pela Faculdade Legale. Advogada. E-mail de contato: priscillamenezes@outlook.com.
} 
Keywords: Revenge porn; Gender-based violence; Civil responsibility; Right to deindexation; cyberspace.

\section{CONSIDERAÇÕES INICIAIS}

Em 1984, o escritor canadense de ficção científica William Gibson cunhou o termo "ciberespaço" (cyberspace) para designar o espaço criado pelas comunicações mediadas por computador.

Para além da ficção científica, destaca-se a notória e exponente revolução da internet e da informática, que afetaram significativa e permanentemente o modo de vida da humanidade e as formas de comunicação. É dizer, as comunicações nunca foram tão ágeis, amplas e difusas como agora (COLOMBO, FACCHINI NETO, 2017).

A criação de um mundo virtual paralelo ao mundo físico trouxe inúmeras benesses, especialmente no que diz respeito à facilidade da obtenção de informações e à agilização de operações diversas. Por outro lado, quando se considera o ciberespaço como um expoente da liberdade de expressão e da democracia, portanto livre de censura, nascem questões sensíveis ante à ausência de filtros sobre o que é postado na rede.

Nesse contexto da inegável disseminação de redes sociais e excesso de exposição do pensamento e da vida privada, surge a possibilidade de aviltar os direitos fundamentais que tutelam a imagem, a honra, a privacidade e a intimidade, inclusive de forma criminosa, como acontece com a divulgação não consentida de imagens e vídeos íntimos, mais conhecida como revenge porn ou pornografia de vingança. A capilaridade da propagação de conteúdo em redes sociais ganha proporções inimagináveis, já que a interação entre usuários de plataformas digitais é instantânea.

Por conseguinte, na seara cível, surge uma celeuma no que concerne à responsabilidade civil de provedores de conteúdo de terceiros em relação à pornografia de vingança. Veja-se que a problemática está na vulneração de determinados direitos fundamentais, decorrente do mau uso das plataformas de provedores de conteúdo, que permitem que terceiros criem e divulguem materiais próprios, sem que haja prévio controle editorial.

Além da análise da possibilidade de reparação civil do dano por esses provedores de conteúdo de terceiros, com estudo sobre a legislação aplicável e sobre a jurisprudência empregada nos casos concretos de destaque, é importante também elucidar alguns 
mecanismos notórios de repressão à pornografia de vingança, por meio do direito comparado, e propor formas utilizadas para coibir a prática ao redor do mundo.

O tema abordado tem um cunho sociológico complexo. Apesar de ser uma prática ilícita que pode atingir qualquer cidadão, é fato notório e manifesto que a pornografia de vingança tem as mulheres como as principais vítimas, visto que “(...) nossa sociedade ainda segue normas rígidas e tradicionais de conduta, que associam a sexualidade das mulheres a ideais de recato, privacidade e falta de direito ao prazer." (BATISTA, 2015)

Dada a relevância e atualidade do tema, é categórica a necessidade de tratar a divulgação não consentida de imagens íntimas como meio de violência de gênero, que se refere a comportamentos que causem danos físicos, psicológicos ou sexuais aos atores da relação, ainda que dentro do "livre" ciberespaço (BATISTA, 2015), entendendo a dinâmica social a partir da imposição da mulher a um papel secundário, devendo ser imagem de recato e retidão, desprovida de qualquer direito ao próprio prazer ou satisfação sexual.

Assim, o artigo proposto utiliza-se de método dedutivo, empregando, como técnica de pesquisa: levantamento bibliográfico, estudo de direito comparado, análise de reportagens de jornais de grande circulação, pesquisa jurisprudencial e análise legislativa.

\section{O PAPEL DA MULHER NA SOCIEDADE E A PORNOGRAFIA NÃO CONSENTIDA COMO INSTRUMENTO DE VINGANÇA}

O papel da mulher na sociedade segue padrões socioculturais determinados por uma ordem dominante, em que os homens ocupam papel privilegiado e de destaque, enquanto às mulheres cabe um papel secundário, frequentemente atrelado à reprodução e cuidado com a casa e com a família - e aí, incluído o cuidado com o próprio homem/marido (BEAUVOIR, 1967; BOURDIEU, 2014). Desta forma, é retirada da mulher, por convenções sociais que imperam em grande parte do mundo, a liberdade de ser quem ela é (ou quer ser). Vários teóricos se debruçam sobre a necessidade da revisão do papel da mulher pela sociedade, tendo em vista o pleno exercício de seus direitos, sobretudo baseados na igualdade entre os seres humanos. Portanto, é neste contexto que

a pornografia de vingança aparece como um mecanismo contemporâneo de manutenção da ordem. O discurso não possui nada de inovador: é a punição da mulher que nega ou subverte o papel social que lhe foi imposto. O método, no entanto, adaptou-se às novas formas de realizar (e dar publicidade) a humilhação social. As redes sociais podem ser também usadas como instrumento de controle das mulheres. (BUZZI, 2015). 
Assim, como um espelho da hierarquia social, a hierarquia sexual, que é socialmente construída, encontra na inferiorização das mulheres uma forma de repetição da realidade imperativa da sociedade. Nesta perspectiva, é delegado à mulher um papel secundário, em que ocupe posição de menor relevância, fazendo com que a divulgação de qualquer conteúdo que desconstrua esta imagem de recato e santidade possa criar danos irreversíveis à sua personalidade, repercutindo na negação de qualquer imagem que tenha sido socialmente construída e, por consequência, destruindo seu caráter, sua imagem profissional, sua imagem social e até mesmo seu amor próprio e sua autoestima. Em alguns casos, em razão dos danos psicológicos causados por essa divulgação não consentida de imagens tidas como vexatórias, se torna tão doído se recompor que algumas mulheres chegam a por fim à própria vida. Esta constatação justifica o porquê de grande parte das vítimas de pornografia de vingança serem mulheres: quando o mesmo fato acontece com os homens, ainda que haja danos à sua reputação em alguns casos, na maioria das vezes se reforça seu caráter viril.

A respeito da caracterização da conduta, discute-se ainda se a terminologia "pornografia de vingança" não traria em si um conceito altamente machista e carregado de estereótipos. Partindo-se da compreensão de pornografia como sendo " "1. tudo o que se relaciona à devassidão sexual; obscenidade, licenciosidade; indecência. (ou) 2. Caráter imoral de publicações, gravuras, pinturas, cenas, gestos, linguagem"; há quem discuta, inclusive, a aplicabilidade do termo com conotações sexistas, visto que a divulgação não consentida de conteúdo íntimo pode configurar uma classificação imprópria destas imagens como algo ligado à perversão sexual, como se a intenção da vítima, desde o início, fosse se colocar em uma posição de devassidão, desconsiderando-se, assim, a intimidade e a confiança que muitas vezes permeiam a obtenção destas imagens.

Além disto, o termo "vingança" pode ser empregado com os seguintes significados:

1. Ação de se vingar, de causar dano físico, moral ou prejuízo a alguém para reparar uma ofensa, um dano ou uma afronta causada por essa pessoa.

2. Ato retaliativo contra quem seria o causador de uma ofensa ou de um prejuízo.

3. Qualquer tipo de punição, castigo; tudo o que pode castigar ou causar sofrimento: a prisão foi uma vingança por seus crimes. (Dicionário Online de Português, 2020). ${ }^{2}$

Ao entender o termo "pornografia de vingança" como a ação de se vingar, causando dano físico, moral, ou prejuízo a alguém para reparar uma ofensa, dano ou afronta causada

\footnotetext{
${ }^{1}$ Verbete "pornografia". Disponível em dicio.com.br/pornografia, acesso em 20/07/2020.

${ }^{2}$ Verbete "vingança". Disponível em dicio.com.br/vingança, acesso em 20/07/2020.
} 
por essa pessoa, utilizando-se do caráter imoral do conteúdo publicado, carregado de devassidão sexual, indecência e obscenidade, impõe-se à vítima uma condição de causadora dos motivos pelos quais a vingança foi perpetrada, tornando-a menos vítima e trazendo ao ato uma falsa sensação de realização de justiça, visto que o autor busca reparar ou, ainda, devolver algum ato que a vítima tenha provocado, ainda que este ato seja a traição ou até mesmo o término de um relacionamento.

Assim, ao se utilizar das redes sociais para propagar imagens íntimas de uma mulher no espaço cibernético, se impõe a ela uma severa condenação, uma vez que a sociedade interpreta que uma mulher que "se dá o respeito" não deveria se colocar nestas situações. Desconsidera-se, assim, a própria condição humana da mulher, negando a ela sua própria imagem e intimidade, quando expostas em redes sociais e amplamente divulgadas, contra sua vontade e, na maioria dos casos, enviadas por um ex-parceiro, como meio de chantagem ou intimidação, com imagens que foram obtidas em ambiente íntimo e de confiança entre as partes.

\section{A RESPONSABILIDADE CIVIL DE APLICAÇÕES DA INTERNET EM CASO DE PORNOGRAFIA DE VINGANÇA NO BRASIL}

César Fiuza, em seu "Direito Civil: Curso Completo", define responsabilidade civil a partir do significado de responsabilidade como zelo, cuidado (FIUZA, 2008, p. 274)). Assim, o conceito jurídico de responsabilidade se vincula "ao fato de respondermos pelos atos que praticamos. O autor vale-se da definição de De Plácido e Silva:

\footnotetext{
[...]dever jurídico, em que se coloca a pessoa, seja em virtude de contrato, seja em face de fato ou omissão, que lhe seja imputado, para satisfazer a prestação convencionada ou para suportar as sanções legais, que lhe são impostas.

Onde quer, portanto, que haja obrigação de fazer, dar ou não fazer alguma coisa, de ressarcir danos, de suportar sanções legais ou penalidades, há a responsabilidade, em virtude da qual se exige a satisfação ou o cumprimento da obrigação ou da sanção. (DE PLÁCIDO E SILVA, 1989 apud FIUZA, 2008, p. 274).
}

O instituto da responsabilidade civil, em sentido amplo, “(...) é a obrigação imposta a qualquer pessoa de reparar o dano causado a outrem em decorrência de seus atos, ou pela atividade de pessoas ou coisas dela dependentes" (DIAS, 2004).

Dentro desse instituto, destacam-se dois sistemas configuradores, quais sejam os da responsabilidade subjetiva e objetiva. No primeiro, temos a presença simultânea de três pressupostos: a conduta antijurídica, o dano e o nexo de causalidade. Já no segundo, não há o 
elemento subjetivo, a ação ou omissão voluntária, negligência, imperícia ou imprudência. Basta que se tenha a demonstração do dano e o nexo de causalidade com o agente causador, salvo casos de excludentes da responsabilidade (PARENTONI, 2009).

Sobre a responsabilidade civil quanto a ilicitudes praticadas no ciberespaço, Marcel Leonardi (2012) explica que

Normalmente, atos ilícitos cometidos por meio da Internet envolvem pelo menos três agentes: o autor do ilícito, a vítima e um intermediário. [...] No âmbito da Rede, esse intermediário é, quase sempre, um provedor que oferece aos seus usuários diversos serviços, conforme a natureza de suas atividades: infraestrutura, acesso, correio eletrônico, hospedagem, conteúdo, busca, entre outros. (LEONARDI, 2012, p. 262)

A responsabilidade de intermediários ganhou visibilidade a partir da tendência dessas soluções digitais em monetizar a partir da inserção de conteúdos de usuários. Elas não oferecem o conteúdo: oferecem a ferramenta para que o material seja produzido e postado, de forma que os usuários interajam entre si (BULGARELLI; NERIS; RUIZ; VALENTE, 2016).

Buscava-se entender qual era a medida e os liames da responsabilidade dos provedores de conteúdo de terceiros quanto a atos ilícitos. A jurisprudência do STJ, nesse ponto, encaminhava para responsabilizar a aplicação da Internet quando havia divulgação de conteúdo ofensivo pelos usuários após a notificação extrajudicial, sistema conhecido internacionalmente como notice and takedown ${ }^{3}$. Entretanto, como qualquer pessoa pode requisitar a remoção de algum conteúdo, há risco de censura no caso de publicações lícitas, motivo por que esse método é controverso.

A partir da elaboração do Marco Civil da Internet, lei $n^{\circ} 12.965 / 1$, foram traçados alguns parâmetros normativos acerca dos princípios, garantias, direitos e deveres para o uso da Internet no Brasil. No seu artigo $19^{4}$, a lei alterou o entendimento anterior, isentando os provedores de aplicações de responsabilidade civil até o momento em que receberem uma ordem judicial para remover o conteúdo danoso. Esse novo sistema ficou conhecido como

\footnotetext{
${ }^{3}$ Superior Tribunal de Justiça. Recurso especial n. ${ }^{\circ}$ REsp 1.323.754/RJ 2012/0005748-4. Julgamento em 19 de jun. de 2012.

${ }^{4}$ Art. 19. Com o intuito de assegurar a liberdade de expressão e impedir a censura, o provedor de aplicações de internet somente poderá ser responsabilizado civilmente por danos decorrentes de conteúdo gerado por terceiros se, após ordem judicial específica, não tomar as providências para, no âmbito e nos limites técnicos do seu serviço e dentro do prazo assinalado, tornar indisponível o conteúdo apontado como infringente, ressalvadas as disposições legais em contrário.
} 
judicial notice and takedown ${ }^{5}$. Boa parte da doutrina considerou essa disposição como um bom meio-termo entre a tutela da privacidade e da liberdade.

Não obstante, essa necessidade de ordem judicial pode ser dispensada nos casos da pornografia de vingança se, após notificação expressa da vítima, o provedor se mantiver inerte, conforme artigo $21^{6}$ do referido Marco Civil. É dizer, a depender da sensibilidade da matéria, as aplicações devem adotar o notice and takedown como regra. Vale, nesse caso, o procedimento extrajudicial, sob pena da aplicação ser solidariamente responsável.

Recentemente, em 28 de maio de 2020, o STJ condenou uma aplicação da Internet a pagar indenização a uma mulher que, após o fim de um relacionamento, teve fotos íntimas divulgadas sem sua autorização numa rede social por seu ex-companheiro ${ }^{7}$.

\begin{abstract}
"Essa decisão representa um grande marco para a sociedade. Ela permite aos titulares dos dados o poder de limitar que sua intimidade seja exposta e ainda impõe uma responsabilidade de moderação e controle para as empresas fornecedoras de soluções de redes sociais", avalia o ethical hacker e professor do Instituto Brasileiro de Mercados de Capitais (Ibmec/DF) Alex Rabello. (BRASIL 61, 2020)
\end{abstract}

Dessa forma, fica clara a responsabilidade subjetiva dos provedores em caso de omissão, ou seja, da sua inatividade em remover o conteúdo, apesar da notificação extrajudicial ou judicial.

\title{
4 MECANISMOS JURÍDICOS COMBATIVOS À PRÁTICA DA PORNOGRAFIA DE VINGANÇA
}

Para além da seara Penal, com a criminalização da conduta do revenge porn, importa que se analise e se proponha medidas preventivas e repressivas à prática também na área cível, inclusive com inspiração no direito comparado. Neris, Ruiz e Valente (2017), compilaram os mecanismos de destaque no mundo sobre o assunto.

A província de Manitoba, no Canadá, criou, no ano de 2016, o Intimate Image Protection Act, com medidas que incluem: o direito de pedir indenização a quem distribui as

\footnotetext{
${ }^{5}$ Superior Tribunal de Justiça. Recurso especial n. ${ }^{\circ}$ REsp 1.642.997/RJ 20160272263-4. Julgamento em 12 de set. de 2017.

6 Art. 21. O provedor de aplicações de internet que disponibilize conteúdo gerado por terceiros será responsabilizado subsidiariamente pela violação da intimidade decorrente da divulgação, sem autorização de seus participantes, de imagens, de vídeos ou de outros materiais contendo cenas de nudez ou de atos sexuais de caráter privado quando, após o recebimento de notificação pelo participante ou seu representante legal, deixar de promover, de forma diligente, no âmbito e nos limites técnicos do seu serviço, a indisponibilização desse conteúdo.

${ }^{7}$ Notícia extraída do site oficial do Superior Tribunal de Justiça. "Rede social pagará indenização por divulgação não autorizada de fotos íntimas, mesmo sem exposição do rosto". Brasília, 28 de mai. de 2020.
} 
imagens íntimas sem consentimento, ou foi negligente ao obtê-lo, além de pedir a devolução ou destruição do material íntimo; a assistência para que o material seja retirado da Internet; a assistência para resolver conflitos com quem tenha posse da imagem ou que a distribuiu; e o fornecimento de informações sobre remédios legais, principalmente.

A Nova Zelândia criou, em 2015, o Harmful Digital Communications Act, que estabeleceu uma agência, a Net Safe, para investigar e resolver casos de comunicação digital danosa. A agência facilita que se chegue a soluções extrajudiciais, além de aconselhar as vítimas, orientar sobre segurança na Internet, educar o público em geral e colaborar com os provedores de conexão e conteúdo para que a lei tenha eficácia.

Na Dinamarca, foram feitos materiais educativos sobre o assunto em portais oficiais sobre educação. No ano de 2016, o Ministério da Educação promoveu uma campanha para jovens com a hashtag "\#stopdigselv", da qual participaram influenciadores digitais famosos, que produziram vídeos sobre a questão, alcançando quase 1 milhão de visualizações. Em 2017, as escolas contaram com um hotline para que os alunos se reportem ou tirem dúvidas sobre como lidar com a situação. Na seara das políticas públicas, há a previsão de capacitação e treinamento de pessoas em instituições investigativas e judiciárias, visando a uma maior denúncia do crime, além de um melhor preparo dos funcionários para atendimento e orientação às vítimas.

$\mathrm{Na}$ Alemanha, a decisão da Corte Federal de Justiça que estabeleceu que o consentimento da posse de imagens íntimas pelo parceiro cessa ao fim do relacionamento ganhou destaque internacional. A Corte considerou os direitos da personalidade da exparceira, já que o conteúdo sexual das imagens era de índole privada.

Na Austrália, o governo promoveu, em 2017, um portal para assistir vítimas de abusos pelo uso de sua imagem. Nesse site as vítimas poderão acessar as leis aplicáveis em cada estado sobre essa prática, receber auxílio para conseguir a retirada do conteúdo danoso, instruções para se reportar à polícia, modelos de petição, etc.

Algumas iniciativas surgidas na sociedade civil organizada também merecem destaque e possuem grande relevância no combate à prática da pornografia de vingança, como é o caso da Women's Justice Now ${ }^{8}$, da Organização Nacional para Mulheres da cidade de Nova Iorque; o The Badass Army", uma organização não governamental, cuja sigla significa "lutando contra o compartilhamento degradante e abusivo de selfies (Battling Against Demeaning \& Abusive

\footnotetext{
${ }^{8}$ Disponível em https://nownyc.org/womens-justice-now/issues/know-your-rights-revenge-porn/.

${ }^{9}$ Disponível em https://badassarmy.org/.
} 
Selfie Sharing); o Rights of Women - helping women through the law ${ }^{10}$, uma organização do Reino Unido; Women's aid, na Irlanda; além de inúmeras iniciativas na África, Ásia, Oceania, Oriente Médio. ${ }^{11}$ Grande parte das iniciativas se inserem no âmbito educacional e de apoio psicológico e de orientação jurídica sobre o que deve ser feito nestes casos.

Diversos sítios eletrônicos e páginas em mídias sociais possuem conteúdo direcionado a mulheres vítimas de divulgação não consentida de suas imagens, dada a relevância social do tema e a consequente necessidade de apoio a estas vítimas. As páginas disponibilizam desde instruções até prestação de serviços jurídicos para que a vítima busque a devida proteção jurisdicional do Estado frente ao abuso que sofreu, inclusive no sentido de informar às pessoas sobre a gravidade da conduta de espalhar conteúdo de cunho íntimo sem o consentimento das pessoas que ali figuram.

No Brasil, há uma atual carência de políticas públicas específicas para tratar da matéria. Há um canal unificado do Ministério da Mulher, da Família e dos Direitos Humanos, que repassam orientações e registram denúncias de violência contra crianças, mulheres, idosos e outros grupos socialmente vulneráveis, inclusive crimes virtuais. Contudo, é possível ver que a criação de canais específicos de auxílio e orientação a vítimas, aliada a políticas educacionais, oferece maior eficácia e agilidade ao tratamento da pornografia de vingança.

Apesar dessa nítida carência de políticas públicas voltadas especialmente para o tema, um mecanismo jurídico que ganha força no Brasil e que certamente auxilia na preservação da intimidade da vítima, bem como na diminuição dos impactos negativos da prática do revenge porn, é o direito à desindexação de termos de pesquisa relacionados a fatos desabonadores em aplicativos de busca, como o Google e o Yahoo!.

$\mathrm{O}$ direito ao esquecimento na internet, através do direito à desindexação, restou fortalecido no Recurso Especial de $n^{\circ}$ 1.660.168/RJ da $3^{\text {a }}$ Turma do STJ - Superior Tribunal de Justiça, julgado em 08/05/2018, em que se discutiu a possibilidade de se determinar, aos provedores de aplicação de busca na internet, que façam o rompimento do vínculo estabelecido entre o nome do prejudicado e a notícia apontada nos resultados.

O STJ decidiu pela possibilidade de desindexação dos termos nos resultados de busca a respeito dos fatos que desabonavam a autora. Isso foi, sem dúvidas, importantíssimo precedente na definição da aplicabilidade desse direito quanto a fatos negativos e aviltantes à

10 Disponível em: https://rightsofwomen.org.uk/get-information/violence-against-women-and-internationallaw/revenge-porn-online-abuse-and-the-law/.

${ }^{11}$ Para mais informações, acesse: https://mashable.com/feature/global-fight-against-revenge-porn/. 
honra do indivíduo, pelo que se faz plenamente cabível também em situação de divulgação não-consentida de pornografia.

\section{CONSIDERAÇÕES FINAIS}

A Internet efetivamente alterou o processo de interação humana. A modernidade líquida, traçada por Bauman (2011), é eivada por uma fluidez e inconstância nas relações. Há dois fenômenos em destaque: a crise da privacidade e a decadência das relações interhumanas. "A pornografia de vingança lida com a inconsistência dos amores hodiernos e a liquidez dos dados informáticos, perpassando o privado e o público numa velocidade sem precedentes.” (BORGES; PILOTO, 2016)

Quanto aos aspectos práticos no tratamento do revenge porn, para além das questões do Direito Penal, insurge o debate na seara cível a respeito da responsabilidade de aplicações da internet sobre conteúdo postado por terceiros.

Anteriormente à lei $n^{\circ} 12.965 / 2014$, utilizava-se o sistema da notificação extrajudicial a fim de gerar a obrigação dos desses serviços para retirar conteúdos sensíveis. O Marco Civil sedimentou esse entendimento para a exposição não-consentida de conteúdo sexual, no seu artigo 21, pelo que não é necessária uma notificação judicial para, só então, determinar a remoção do conteúdo.

A respeito dos mecanismos de combate ao revenge porn, além dos instrumentos educacionais, sobre os quais a Dinamarca insurge como um bom exemplo a ser seguido, emerge, no Brasil, a necessidade de se criar políticas públicas federais específicas, a fim de prover um maior suporte e orientação às vítimas, como ocorre na Austrália. Ademais, o direito à desindexação de termos em aplicativos de busca na internet mostra-se um efetivo mecanismo, que tem o escopo de preservar a intimidade e honra da vítima quanto ao fato desabonador.

A complexidade desse tema e da problemática envolvida revela que, para que haja uma minimização dos efeitos negativos da pornografia de vingança, deve haver uma cooperação que envolve múltiplos setores da sociedade e do governo, a fim de que haja conscientização e desconstrução de ideologias sexistas, que culminam na violência de gênero, inclusive no ciberespaço. 


\section{REFERÊNCIAS}

ARAÚJO, Laisa Ribeiro de; COSTA, Carlos; CRUZ, Marco Aurélio Rodrigues da Cunha e. A responsabilidade civil do provedor de conteúdo por violações à honra praticadas por terceiros: antes e pós-Marco Civil da Internet. Revista de Direito do Consumidor | vol. 99/2015 | p. 185 - 231 | Maio - Jun / 2015.

BATISTA, Amanda Simões da Silva. Responsabilidade civil e penal pelo dano à honra, à imagem e à intimidade das vítimas de pornografia de vingança. Disponível em: http://www.repositorio.ufc.br/bitstream/riufc/25834/1/2015_tcc_assbatista.pdf. Acesso em: 11 jun. 2020.

BAUMAN, Zygmunt. Modernidade líquida. Rio de Janeiro (RJ): Zahar, 2011.

BRASIL, Lei n 12.965, de 23 abr. 2014. Estabelece princípios, garantias, direitos e deveres para o uso da Internet no Brasil. Diário Oficial da União, Brasília, 23 abr. 2014. Disponível em: http://www.planalto.gov.br/ccivil_03/_ato2011-2014/2014/lei/112965.htm. Acesso em: 13 jun. 2020.

BRASIL, Superior Tribunal de Justiça. Recurso especial n. ${ }^{\circ}$ REsp 1.323.754/RJ 2012/0005748-4. Recorrente Google Brasil Internet Ltda. Recorrido Grasiele Salme Leal. Relator: ANDRIGHI, Nancy. Diário da Justiça eletrônico, Brasília - DF, 19 de jun. de 2012. Disponível em: https://www.jusbrasil.com.br/diarios/60824316/stj-23-10-2013-pg-3339. Acesso em: 13 jun. 2020

BRASIL, Superior Tribunal de Justiça. Recurso especial n. ${ }^{\circ}$ REsp 1.642.997/RJ 20160272263-4. Recorrente Facebook Serviços Online do Brasil Ltda. Recorrido Fernando Candido Da Costa. Relator: ANDRIGHI, Nancy. Diário da Justiça Eletrônico, Brasília DF, 12 de set. de 2017. Disponível em: https://stj.jusbrasil.com.br/jurisprudencia/499418489/recurso-especial-resp-1642997-rj-20160272263-4/inteiro-teor-499418498. Acesso em: 13 jun. 2020.

BRASIL, Superior Tribunal de Justiça. Recurso especial n. ${ }^{\circ}$ 1.660.168 RJ 2014/0291777-1. Recorrente Yahoo Do Brasil Internet Ltda, Google Brasil Internet Ltda. Recorrido D. P. N. Relatora: ANDRIGHI, Nancy. Diário da Justiça eletrônico, Brasília - DF, 08 de mai. de 2018. Disponível em: https://stj.jusbrasil.com.br/jurisprudencia/595923405/recurso-especialresp-1660168-rj-2014-0291777-1/inteiro-teor-595923409?ref=juris-tabs. Acesso em: 26 mai. 2020

BORGES, Clara Maria Roman; PILOTO, Alessandra Calisto. Relações líquidas: a pornografia de revanche no ciberespaço. Disponível em:

https://pdfs.semanticscholar.org/f254/6f17193e6c57097b1eb289025f47d5dac25e.pdf. Acesso em: 13 jun. 2020.

BOURDIEU, Pierre. A Dominação Masculina. 12. ed. Rio de Janeiro: Bertrand Brasil, 2014. 160 p.

BEAUVOIR, Simone de. O segundo sexo: A experiência vivida. 2. ed. São Paulo: Difusão Europeia do Livro, 1967. 
BULGARELLI, Lucas; NERIS, Natália; RUIZ, Juliana Pacetta; VALENTE, Mariana Giorgetti. $O$ corpo é o código: estratégias jurídicas de enfrentamento ao revenge porn no Brasil. São Paulo (SP): InternetLAB, 2016.

BUZZI, Vitória de Macedo. Pornografia de vingança: Contexto histórico-social e abordagem no direito brasileiro. Monografia (Graduação em Direito), Departamento de Direito, Universidade Federal de Santa Catarina. Florianópolis, 2015.

COLOMBO, Cristiano; FACCHINI NETO, Eugênio. Ciberespaço e conteúdo ofensivo gerado por terceiros: a proteção dos direitos de personalidade e a responsabilização civil dos provedores de aplicação, à luz da jurisprudência do Superior Tribunal de Justiça. Rev. Bras. Polít. Públicas, Brasília, v. 7, nº 3, 2017 p. 216-234.

DIAS, Ronaldo Brêtas de Carvalho. A responsabilidade civil do estado no direito brasileiro. Boletim Técnico. Belo Horizonte: Escola Superior de Advocacia da OAB/MG, n. ${ }^{\circ}$ 01. p. 11-38, jan./jun. 2004. p. 11.

FIUZA, Cesar. Direito civil: curso completo. Belo Horizonte: Del Rey Editora, 2008.

GIBSON, William. Neuromancer. São Paulo (SP): Aleph, 2013.

NERIS, Natália; RUIZ, Juliana Pacetta; VALENTE, Mariana Giorgetti. Análise comparada de estratégias de enfrentamento a "revenge porn" pelo mundo. Rev. Bras. Polít. Públicas, Brasília, v. 7, nº 3, 2017 p. 333-347.

Ministério da Mulher, da Família e dos Direitos Humanos. Brasil, Brasília. Disponível em: https://ouvidoria.mdh.gov.br/. Acesso em: 14 de jun. de 2020.

PARENTONI, Leonardo Netto. Responsabilidade civil dos provedores de serviços na internet: breves notas. Disponível em: https://ambitojuridico.com.br/edicoes/revista67/responsabilidade-civil-dos-provedores-de-servicos-na-internet-breves-notas. Acesso em: 13 jun. 2020.

Rede social pagará indenização por divulgação não autorizada de fotos íntimas, mesmo sem exposição do rosto. Superior Tribunal de Justiça, Brasília, 28 de mai. de 2020. Disponível em: http://www.stj.jus.br/sites/portalp/Paginas/Comunicacao/Noticias/Rede-social-pagaraindenizacao-por-divulgacao-nao-autorizada-de-fotos-intimas--mesmo-sem-exposicao-dorosto.aspx. Acesso em: 12 de jun. de 2020.

STJ condena plataforma digital por manter publicações de fotos íntimas sem autorização da vítima. Brasil 61. Disponível em: https://www.brasil61.com/noticias/stj-condena-plataformadigital-por-manter-publicacoes-de-fotos-intimas-sem-autorizacao-da-vitima-bras200186. Acesso em: 14 de jun. de 2020.

UNITED KINGDOM. Revenge porn, online abuse and the law. Disponível em: https://rightsofwomen.org.uk/get-information/violence-against-women-and-internationallaw/revenge-porn-online-abuse-and-the-law/. Acesso em 20/07/2020. 